\title{
Production of Biogas and Astaxanthin from Fruit and Vegetable Wastes Using an Integrated System
}

\author{
Okyanus Yazgın (D)1, Tugba Keskin-Gundogdu (D) 1,* \\ ${ }^{1}$ Bioengineering Department, Faculty of Engineering, Ege University, Izmir, Turkey
}

\begin{abstract}
The use of fruit and vegetable wastes in biogas production is an attractive option, as it provides simultaneous waste treatment and energy production. The use of the $\mathrm{CO}_{2}$ in biogas for algae cultivation with a zero waste approach would make this process even more attractive. In this way, biogas enrichment, which is traditionally done using economically costly and nonenvironmentally friendly methods, would be improved, and algae cultivation would become more economical. In the first part of this study, the operation conditions for the biogas reactor and the algae reactor for astaxanthin production were optimized separately. Rates of up to $1.2 \mathrm{~L} \mathrm{CH}_{4} /$ day and yields up to $0.5 \mathrm{~L} \mathrm{CH}_{4} / \mathrm{g}$ volatile solids were obtained with a $2.5 \mathrm{~g}$ dry matter/L day organic loading rate with an anaerobic bioreactor, and $5.1 \mathrm{mg} / \mathrm{g}$ astaxanthin was produced by air feeding. When it was decided that sufficient astaxanthin was produced, astaxanthin was obtained using vegetable oils (olive and nut), an environmentally friendly extraction method. In the second part of this study, the anaerobic bioreactor and the algae reactor were integrated, and $6 \mathrm{mg} / \mathrm{g}$ astaxanthin production was observed using fruit and vegetable wastes as the substrate for biogas production and the $\mathrm{CO}_{2}$ in biogas for cultivation of Haematococcus pluvialis and therefore astaxanthin production. The integrated system resulted in higher astaxhantin production with a zero waste approach. Moreover, the residual biomass remaining after extraction was fed back into the biogas reactor as a substrate, adopting a zero waste biorefinery approach.
\end{abstract}

\section{ARTICLE HISTORY}

Received: January 01, 2020

Revised: February 16, 2020

Accepted: March 09, 2020

\section{KEYWORDS}

Fruit-Vegetable Waste, Biogas,

Astaxhanthin,

Biorefinery,

Microalgae

\section{INTRODUCTION}

The depletion of fossil fuel resources has led researchers to investigate alternative sources of clean energy. Biogas, one of those clean energy sources, is based on the conversion of carbon-containing substrates to methane $\left(\mathrm{CH}_{4}\right)$ and carbon dioxide $\left(\mathrm{CO}_{2}\right)$ by anaerobic microorganisms. Biogas is a clean energy source with a high $\mathrm{CH}_{4}$ content compared to petroleum-based natural gas. At the same time, increasing air and land pollution has adversely affected living conditions in recent years, especially in developing countries. One of the reasons for the increase in environmental pollution is the uncontrolled release of organic wastes. Vegetable and fruit wastes make up an important component of organic wastes. One of the

CONTACT: Tugba Keskin-Gundogdu $\square$ keskin.tugba@gmail.com $\equiv$ Bioengineering Department, Faculty of Engineering, Ege University, Izmir, Turkey 
most-studied alternative methods for renewable energy production is the use of vegetable and fruit wastes for biogas production.

Although biogas, a renewable energy source, has an established production process, there are aspects that can be improved. The most important of these is the purification step required to increase the $\mathrm{CH}_{4}$ concentration of biogas and reduce $\mathrm{CO}_{2}$ emissions. The use of algae for $\mathrm{CO}_{2}$ reduction instead of the high-cost chemical/physical methods commonly used at this stage will encourage increased biogas production and make it a more economical, efficient and environmentally friendly process [1]. Different species of microalgae have the ability to produce a variety of bioproducts, including proteins, unsaturated fatty acids, vitamins, and carbohydrates [2]. Recently, Haematococcus pluvialis, one of the increasingly popular species for algal production processes, has been shown to be capable of producing astaxanthin under stress conditions. Astaxanthin is in great demand in important industrial sectors such as animal feed, food and pharmaceuticals. Astaxanthin is a powerful antioxidant and has features such as lipid peroxidation prevention, inflammation prevention, cardiovascular disease prevention, and anti-diabetic and anti-cancer effects [2].

\subsection{Biogas Production}

Biogas is one of the renewable energy sources identified by the European Union (Directive 2001/77 / EC). Biogas can be produced from different biomass sources, such as plant and animal wastes including wastes from forestry and related industries or organic fractions of municipal waste, through an anaerobic digestion process [3]. It is mainly a mixture of $\mathrm{CH}_{4}(50-$ $70 \%$ ) and $\mathrm{CO}_{2}(30-40 \%)$, but different production sources (substrates) can lead to different specific compositions. Anaerobic digestion has four main steps: hydrolysis, acidogenesis, acetogenesis and methanization. Each step is related to a centrophic relationship and involved in different metabolic activities of microorganism consortia [4-6].

In 2012, 598 million tons of urban solid organic waste were produced globally. This waste is expected to reach 1.012 billion tons annually in 2025 [7]. The type of waste making up the highest percentage of that total at 1.1 million tons is vegetable and fruit wastes [8]. When these large amounts of waste end up in regular waste storage facilities, they pollute natural environments. One of the best alternative ways of disposing of these wastes is anaerobic digestion. The main advantage of this process is that it generates biogas that can be used to generate electricity. In addition, the residues can be used as fertilizer [9]. The main limitation of anaerobic decomposition of vegetable and fruit wastes is the low $\mathrm{pH}$ of the wastes and their rapid acidification due to high volatile fatty acid (VFA) production during methanogenic activity $[10,11]$. In order to prevent this, many studies have shown that vegetable and fruit wastes can be mixed with different amounts of other wastes, such as cattle waste. These studies were able to obtain more stable systems. In addition, there are studies that have used only vegetable and fruit waste and eliminated the problems with acidity with the help of two-phase systems $[10,12,13]$. In these systems, the organic loading rate is first "buffered", and thus, a more stable system is obtained in the second stage of methanization [14]. What matters here is identifying an optimal organic loading rate to determine the appropriate reactor type $[11,14,15]$.

\subsection{Biogas Enrichment}

Depending on the end use, different biogas enrichment steps are required. For direct use in vehicle fuel or natural gas lines, the gas must have a high energy content. The energy content of the biogas is directly proportional to the $\mathrm{CH}_{4}$ concentration and can be increased by reducing $\mathrm{CO}_{2}$ in the upstream process. However, enrichment processes are often costly, requiring high energy. It is also very important to minimize or prevent $\mathrm{CH}_{4}$ emissions during the enrichment process. Water washing, cryogenic separation, physical absorption, chemical absorption, membrane separation and pressure release adsorption are the most commonly used enrichment 
methods. Furthermore, in-situ augmentation and biological augmentation methods are also evolving, and their use is increasing [16].

\subsection{Astaxanthin}

Astaxanthin is a xanthophylline, an oxidative derivative of carotenes. Astaxanthin is the main carotenoid pigment found in aquatic animals, including seafood such as salmon, trout, shrimp, lobster and roe, as well as birds such as flamingos and quails [17]. In addition, some microorganisms are very rich in astaxanthin. H. pluvialis, a chlorophyte algae, is believed to be the organism capable of accumulating the highest levels of astaxanthin in nature. Astaxanthin production is especially high under stress conditions to protect algae from adverse environmental changes, such as increased UV radiation and evaporation of pools of water. Commercially grown Haematococcus can accumulate up to $30 \mathrm{~g}$ of astaxanthin per $\mathrm{kg}$ of dry biomass. Before the production of Haematococcus became so commercially widespread, natural astaxanthin sources included krill oil, crayfish oil and Phaffia yeast. However, these sources have low concentrations of astaxanthin, from $0.15 \%$ in oils to $0.40 \%$ in Phaffia yeast. In terms of antioxidant activity, astaxanthin is 65 times stronger than vitamin $\mathrm{C}, 54$ times stronger than $\beta$-carotene, and 10 times stronger than cataxanthin, zeaxanthin and lutein. Astaxanthin is used in food, animal feed, cosmetics, animal breeding, and nutraceuticals, and it has a wide range of applications in pharmaceutical industries [18,19]. At this point, high energy requirements and costly downstream processes such as cell lysis and intracellular product extraction are thought to be the obstacles to microalgae-based production of astaxanthin. Therefore, aside from the optimization of astaxanthin production, another important subject is extraction [20].

\subsection{Extraction of Astaxanthin}

Astaxanthin accumulates in the thick-walled cyst cells of $H$. pluvialis. The thick-walled cell prevents the removal of lipids and astaxanthin. Therefore, various methods of lipid and astaxanthin extraction from $H$. pluvialis, including extraction with various organic solvents and extraction of supercritical $\mathrm{CO}_{2}$, have been investigated. However, disadvantages such as toxicity, high pressure and the need for pre-treatment drying limit the use of such methods [21]. As an alternative to such methods, Kang and Sim [22] proposed extraction with vegetable oils that are eco-friendly, simple, economical and do not require high amounts of energy. Kang and Sim [22] carried out the extraction process by directly mixing the wet $H$. pluvialis culture with soy, corn, grape seed and olive oils without any drying process. Their best reported result was an astaxanthin recovery rate of $93.9 \%$ after 48 hours of extraction, obtained in olive oil. Samori et al. [23] managed to obtain astaxanthin with almond oil without any pretreatment. In addition, with the "milking" method they developed, they were able to extract without killing the algae or reducing photosynthetic activity. Another advantage of these extraction methods is that they successfully maintain the stability of astaxanthin. In all edible oils at room temperature, such as rice bran, mustard, peanut, coconut and palm oils, astaxanthin in its ester form is fairly stable in terms of loss of content and color over four months. Rice bran oil and palm oil were even able to maintain $84-90 \%$ of astaxanthin when heated at $70^{\circ} \mathrm{C}$ for 8 hours [24].

This study evaluates an integrated system in which vegetable and fruit wastes were used as a source for biogas production and the $\mathrm{CO}_{2}$ from biogas production was used as the substrate for astaxanthin production using $H$. pluvialis. At the same time, $H$. pluvialis acts as a biofilter. Plants will be an important alternative for combining biogas and astaxanthin production. Furthermore, within the scope of this study, an environmentally friendly extraction method was used to harvest the astaxanthin produced by stress conditions created after reaching biomass. Instead of toxic chemicals, olive oil and hazelnut oil were used for the extraction of astaxanthin. 
Therefore, the residual biomass remaining after extraction became another source for biogas production, and a zero-waste biorefinery approach was achieved.

\section{MATERIAL and METHODS}

\subsection{Anaerobic Bioreactor and Biogas Production}

$1 \mathrm{~L}$ stirred tank anaerobic reactor with $800 \mathrm{~mL}$ working volume was used for biogas production (Figure 1). The reactor has started with an anaerobic mixed consortium taken from a big industrial scale reactor and basal medium. Magnetic stirring was used and the temperature of the reactor was kept constant at $37^{\circ} \mathrm{C}$ with heating jacket. The biogas produced was measured with microflow meter and the gas content was determined by using gas chromatography.

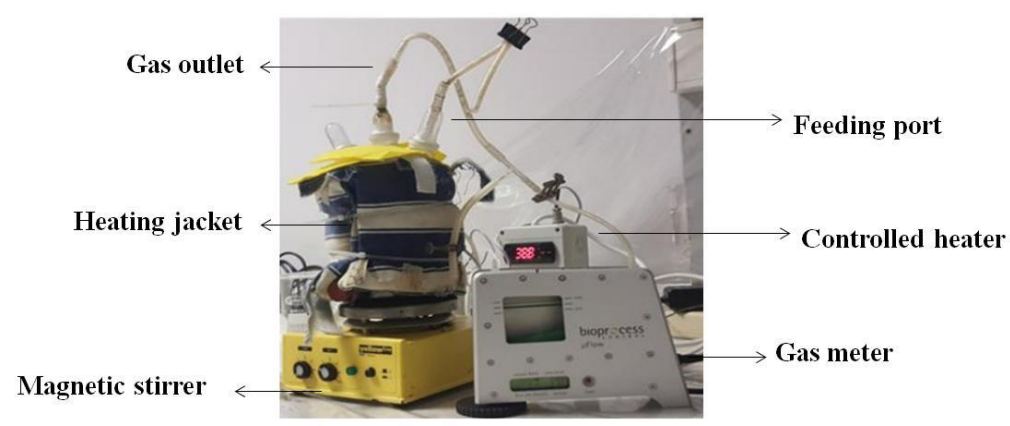

Figure 1. Anaerobic bioreactor

To determine the optimum organic loading rate (OLR) the load was increased gradually as 1, 2, 2.5 and $3.5 \mathrm{~g} \mathrm{DM} /$ Lreactor.day and the feeding was continued until three same data as biogas production obtained. The influent and effluent was taken in order to measure Chemical Oxygen Demand (COD), $\mathrm{pH}$ and dry matter content to follow the system performance.

\subsection{Fruit and Vegetable Wastes and Medium Compositions}

Fruit and vegetable wastes was used as substrate for biogas production. The composition of the waste is; pear, $11.74 \%$, mandarin, $10.82 \%$, grape, $5.86 \%$, orange, $10.71 \%$, apple, $10.36 \%$, tomato, $11.28 \%$, carrot, $9.01 \%$, pepper, $6.33 \%$, cucumber, $8.02 \%$, eggplant, $7.42 \%$ and zucchini, $8.41 \%$. The wastes were collected from a local grocery and the composition was kept constant during study. After chopping into small pieces with grinder the waste was kept at $+4^{\circ} \mathrm{C}$ refrigerator. The basal medium composition is as follows; (mg/L) $\mathrm{NH}_{4} \mathrm{Cl}(1200), \mathrm{MgSO}_{4} \bullet 7 \mathrm{H}_{2} \mathrm{O}$ (400), $\mathrm{KCl}$ (400), $\mathrm{Na}_{2} \mathrm{~S} \bullet 9 \mathrm{H}_{2} \mathrm{O}$ (300), $\mathrm{CaCl}_{2} \bullet 2 \mathrm{H}_{2} \mathrm{O}$ (50), $\left(\mathrm{NH}_{4}\right)_{2} \mathrm{HPO}_{4}$ (80), $\mathrm{FeCl}_{2} \bullet 4 \mathrm{H}_{2} \mathrm{O}$ (40), $\mathrm{CoCl}_{2} \bullet 6 \mathrm{H}_{2} \mathrm{O}(10), \mathrm{KI}(10), \mathrm{MnCl}_{2} \bullet 4 \mathrm{H}_{2} \mathrm{O}(0.5), \mathrm{CuCl}_{2} \bullet 2 \mathrm{H}_{2} \mathrm{O}(0.5), \mathrm{ZnCl}_{2}(0.5), \mathrm{AlCl}_{3} \bullet 6 \mathrm{H}_{2} \mathrm{O}$ (0.5), $\mathrm{NaMoO}_{4} \bullet 2 \mathrm{H}_{2} \mathrm{O}(0.5), \mathrm{H}_{3} \mathrm{BO}_{3}(0.5), \mathrm{NiCl}_{2} \bullet 6 \mathrm{H}_{2} \mathrm{O}(0.5), \mathrm{NaWO}_{4} \cdot 2 \mathrm{H}_{2} \mathrm{O}(0.5)$, Cysteine (10) and $\mathrm{NaHCO}_{3}(6000)$.

\subsection{Astaxhantin Production}

H. pluvialis was kindly taken from the Microalgea Culture Collection of Ege University (EGEMACC), and cultivated in sterilized BG-11 medium at $25^{\circ} \mathrm{C}$ photoautrotpically (5000 lux). The stock culture was maintained in a $250 \mathrm{~mL}$ sterile glass bottle. The inoculation was performed by using RM medium at $10 \%$ concentration to $1 \mathrm{~L}$ bioreactors [25]. $1 \mathrm{~L} / \mathrm{min}$ rate air was fed into the system during stock culture growth and $0.47 \mathrm{~L} / \mathrm{min}$ was fed to integrated system. The rate of air was controlled by using a rotameter. The biomass growth was measured at $680 \mathrm{~nm}$ using UV spectrophotometer (Sigma-Aldrich) and Nuebauer glass was used for cell counting at microscope (Olympus). Astaxhantin was produced under stress condition of 22000 lux light after biomass growth. Different culture stages can be seen in Figure 2. 


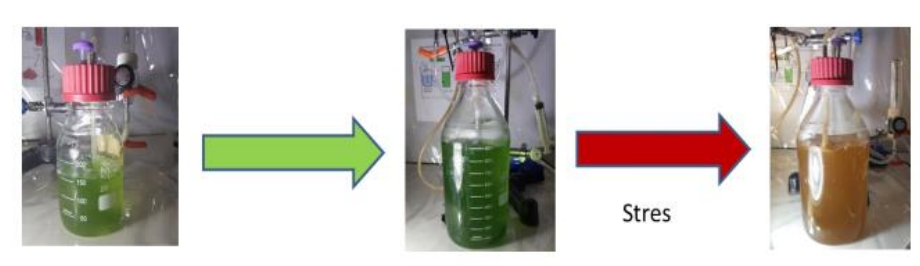

Figure 2. Stock culture, biomass production and astaxhantin production

\subsection{Extraction and Quantification of Astaxhantin}

As it was decided that the algae were kept under stress conditions for sufficient time and sufficient astaxanthin was produced, the cells were harvested by centrifugation at $4500 \mathrm{rpm}$ for 7 minutes. The decision to produce sufficient astaxanthin was made by examining the cells under the microscope and observing that the majority entered the cystic red phase. With this decision, the cells were harvested and the volume of the cells was completed to $15 \mathrm{~mL}$ with distilled water. The cells were then taken to beakers where extraction would take place and 15 $\mathrm{mL}$ of vegetable oil was poured onto them. The vegetable oils used were nuts and olive oils. The oils were poured and stirred at $480 \mathrm{rpm}$ with magnetic stirrer (VELP Scientifica) at room temperature for 48 hours. Subsequently, the astaxanthin extract phase, which is the supernatant, was removed for 1 hour. The obtained astaxanthin extracts were examined under microscope and dilution was performed if necessary and absorbance measurement at $480 \mathrm{~nm}$ on spectrophotometer. In order to determine the best extracting oil, the best results obtained by Kang and Sim (2008) were compared with previously untested hazelnut oil. Cystic cells obtained from the test culture were extracted according to the above procedure. The extraction process was performed by mixing $7.5 \mathrm{~mL}$ of $7.5 \mathrm{~mL}$ of hazelnut oil and $7.5 \mathrm{~mL}$ of olive oil to $7.5 \mathrm{~mL}$ of olive oil which was completed to $15 \mathrm{~mL}$ with pure water (Figure 3).

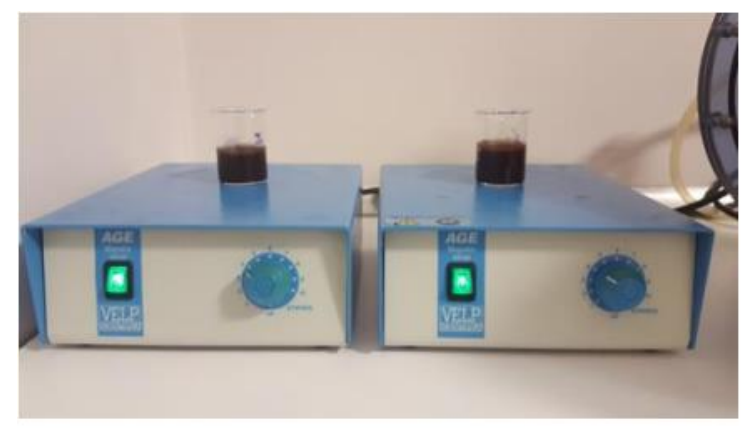

Figure 3. Extraction of astaxhantin

For the determination of the amount of astaxanthin, standard astaxanthin (Sigma-Aldrich) was dissolved in the selected vegetable oil (olive oil for better extraction results) and standard solutions were prepared in different concentrations. Then the absorbance of the extracts was measured at $680 \mathrm{~nm}$ and the concentration was determined from the calibration equation (Figure 4).

\subsection{Integrated System}

The integrated system is prepared by connecting the anaerobic bioreactor and the photobioreactor, as can be seen in Figure 5 and Figure 6. A flowmeter was used before and after the photobioreactor to determine the quantities of gas produced and used. In addition, samples were taken from gas sampling ports with gas syringe and analyzed in gas chromatography. In addition, 0.22 micron air filter (Sartorius) was used at the inlet and outlet of the photobioreactor to prevent contamination. 


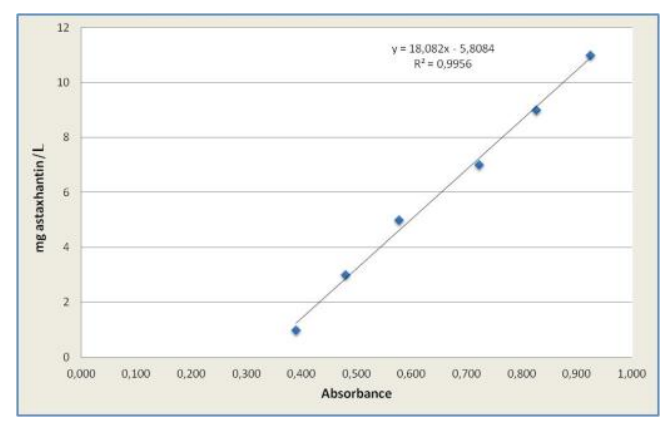

Figure 4. The calibration graph of astaxhantin

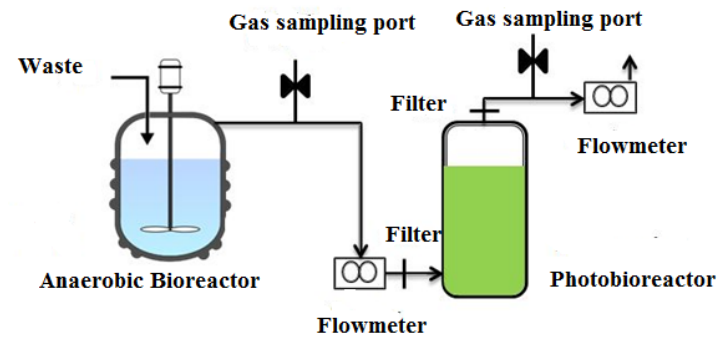

Figure 5. Experimental set-up (schematic)

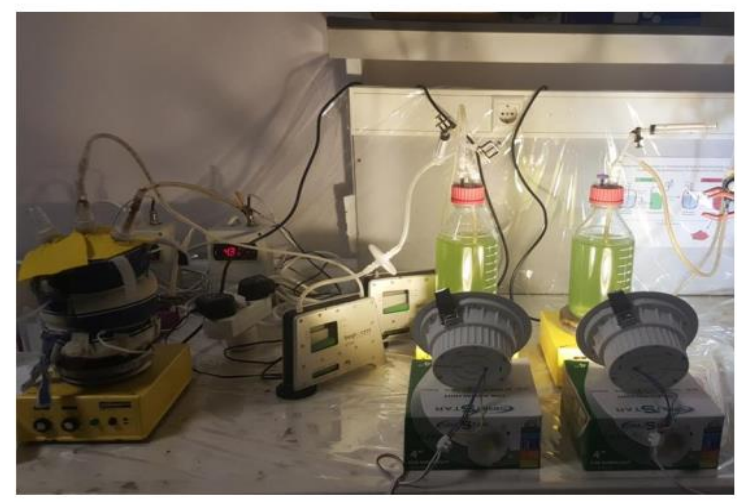

Figure 6. Integrated system

\subsection{Analytical methods}

$\mathrm{pH}$ was measured by $\mathrm{pH}$ meter (Sartorious), COD and Dry Matter (DM) analysis was performed according to standard methods. The gas composition was measured according to our previous studies [26].

\section{RESULTS and DISCUSSION}

\subsection{Waste Characterization}

It can be seen that the data obtained as a result of the characterization of the vegetablefruit waste is similar with literature values (Table 1).

\subsection{Biogas Production}

The best results in the organic loading rate optimization experiments were obtained at 2.5 $\mathrm{g}$ dry matter $(\mathrm{DM}) / \mathrm{L}$ day. As can be seen in Figure 7, the highest efficiency and rate values were obtained for this OLR value. The maximum rate obtained was $1.075 \mathrm{~L} \mathrm{CH}_{4} / \mathrm{L}$ day, and the maximum yield was $0.512 \mathrm{~L} \mathrm{CH}_{4} / \mathrm{g}$ volatile solids (VS). The mean values were $0.737 \mathrm{~L}$ $\mathrm{CH}_{4} / \mathrm{L}$.day and $0.351 \mathrm{~L} \mathrm{CH}_{4} / \mathrm{g}$ VS. In comparison with the literature, Bouallagui et al. [28] and Scano et al. [15] reported higher yields ( 0.45 and $0.43 \mathrm{~L} \mathrm{CH}_{4} / \mathrm{g} \mathrm{VS}$, respectively) with the same loading rate $(2.5 \mathrm{~g} \mathrm{DM} / \mathrm{L}$ day). However, these two studies used large-scale tubular reactors (18 $\mathrm{L}$ and $0.95 \mathrm{~m}^{3}$, respectively), which is the main reason for the difference in yields. Moreover, inoculum and the characteristics of the input waste are also important parameters. 
Table 1. Characterization values of fruit and vegetable wastes in literature

\begin{tabular}{ccccc}
\hline Dry matter $(\%)$ & Volatile matter $(\%)$ & COD & $\mathrm{pH}$ & Reference \\
\hline 10 & 88 & $120 \mathrm{~g} / \mathrm{kg}$ (total) & 4.2 & {$[10]$} \\
11 & 87 & - & 4.2 & {$[10]$} \\
9.15 & 84 & $49 \mathrm{~g} / \mathrm{L}$ (soluble COD) & 4.1 & {$[27]$} \\
8.7 & 86 & - & - & {$[15]$} \\
\hline
\end{tabular}

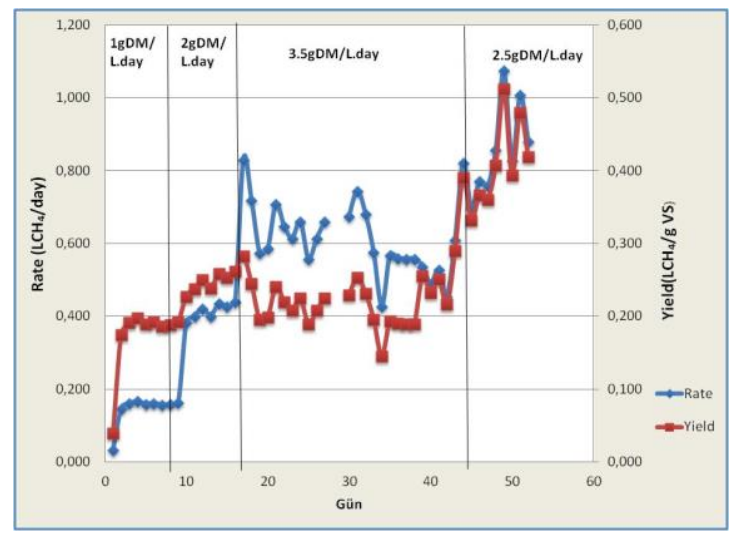

Figure 7. Rate and yield values during biogas production

The best results in terms of total biogas and $\mathrm{CH}_{4}$ content were obtained with a $2.5 \mathrm{~g} \mathrm{DM} / \mathrm{L}$ day organic loading rate (Figure 8). The highest daily total biogas and $\mathrm{CH}_{4}$ values obtained with this OLR were determined as 1154 and $860 \mathrm{~mL}$, respectively. The highest obtained $\mathrm{CH}_{4}$ content was $75.6 \%$, and the average $\mathrm{CH}_{4}$ percentage was $67 \pm 5(\%)$. Bouallagui et al. [10], Raynal et al. [13] and Qiao et al. [27] reported 74\%, 69\% and 63\% $\mathrm{CH}_{4}$, respectively. It can be seen that the results obtained in this study are consistent with the literature data. The mean $\mathrm{pH}$ values were determined as $7.45 \pm 0.34,7.64 \pm 0.09,7.50 \pm 0.13$ and $7.31 \pm 0.17$ at rates of $1,2,2.5$ and $3.5 \mathrm{~g} \mathrm{DM} / \mathrm{L}$ day, respectively. The $\mathrm{pH}$ value was decreased by increasing OLR and reached a maximum value at $3.5 \mathrm{~g} \mathrm{DM} / \mathrm{L}$ day. The reasons for this decrease are that the higher the organic loading rate, the more acidic waste is fed into the reactor and also the occurrence of acidification due to the high amount of volatile fatty acid production. Methanogenic activity is also reduced due to this acidification. That's why better results for biogas production, rate and efficiency values are obtained at the feed rate of $2.5 \mathrm{~g} \mathrm{DM} / \mathrm{L}$ day rather than 3.5. In other studies in the literature, this phenomenon is mentioned and an optimum $\mathrm{pH}$ range between 7 and 8 is reported [11,14].

The chemical oxygen demand (COD) value of the effluent was measured as 200 and 600 $\mathrm{mg} / \mathrm{L}$ with 1 and $2 \mathrm{~g} \mathrm{DM} / \mathrm{L}$ day OLRs, respectively (Figure 9). By increasing the rate to $3.5 \mathrm{~g}$ $\mathrm{DM} / \mathrm{L}$ day, the COD value was increased to $10,000 \mathrm{mg} / \mathrm{L}$, and it was reduced to $2000 \mathrm{mg} / \mathrm{L}$ with a $2.5 \mathrm{~g} \mathrm{DM} / \mathrm{L}$ day rate. This increase in COD with OLR is due to the fact that as the feed rate increases, there is much more organic matter than the microorganisms can consume, and their concentration in the environment gradually increases. It can be seen that the amount of COD decreases again when the rate is reduced to $2.5 \mathrm{~g} \mathrm{DM} / \mathrm{L}$ day. The percent COD removal values support this argument (Figure 8). When comparing these values to the COD removal values in the literature, Bouallagui et al. [10] and Raynal et al. [13] reported average COD removal rates of $96 \%$ and $87.5 \%$, respectively. In this study, the mean COD removal rate was found to be $91.4 \pm 3.3 \%$ at a loading rate of $2.5 \mathrm{~g} \mathrm{DM} / \mathrm{L}$ day. 


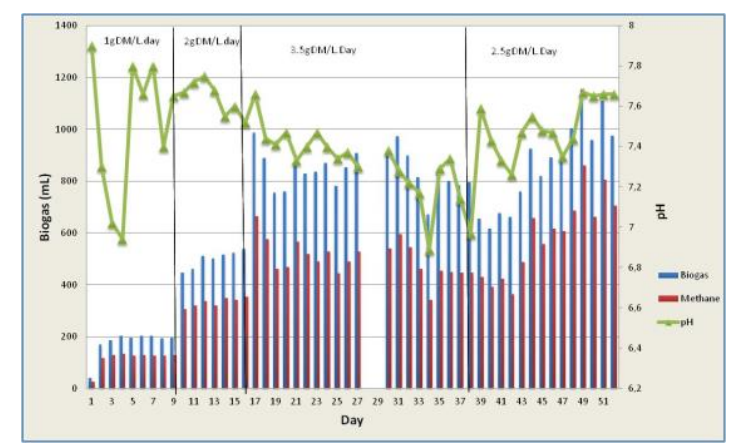

Figure 8. Biogas production and $\mathrm{pH}$ values

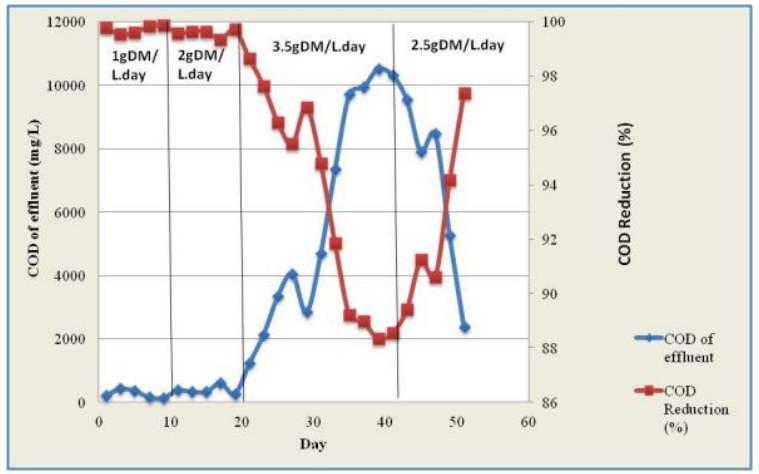

Figure 9. Biogas production and $\mathrm{pH}$ values

\subsection{Astaxanthin Production}

Comparing hazelnut oil and olive oil, the best extraction was obtained with olive oil. At the end of 48 hours of extraction, 200 times diluted hazelnut oil extracts exhibited $0.545 \pm 0.003$ absorbance at $480 \mathrm{~nm}$, while 200 times diluted olive oil extract exhibited $1.265 \pm 0.005$ absorbance. As can be seen in Figures 10 and 11, there is a higher number of non-lysed and astaxanthin-containing cells in the extraction with hazelnut oil than in olive oil.

\subsection{Integrated System}

Figures 12 and 13 show that the biogas-fed algae culture and the comparison culture (airfed) in the integrated system showed similar growth trends. This shows that algae grown with biogas can use the $\mathrm{CO}_{2}$ in biogas. In terms of cell concentration, both cultures reached a concentration of $12 \times 10^{4}$ cells $/ \mathrm{mL}$ and then entered the death phase. Cultivation under similar conditions is described in Imamoglu et al. [29], where the culture reached a concentration of 95 x $10^{4}$ cells/mL. Imamoglu et al. [29] used RM food medium, as in this study, and produced a similar air condition, but used a much higher air feed rate $(0.8 \mathrm{~L} / \mathrm{min}-4 \mathrm{vvm})$. They also supplied intermittently pure $\mathrm{CO}_{2}$. Although this resulted in positive effects in terms of growth, energy costs should be reviewed in terms of profit and loss. In this study, $0.47 \mathrm{~L} / \mathrm{min}, 0.47 \mathrm{vvm}$ of air was fed to the air-fed culture to ensure that the amount of $\mathrm{CO}_{2}$ coming from the anaerobic reactor would be the same as the amount of air fed to the comparison culture. However, since the biogas-grown culture eliminates unwanted $\mathrm{CO}_{2}$ in the biogas inexpensively (even without the use of a pump), the amount of $\mathrm{CO}_{2}$ to be supplied to the culture can be easily increased by using an anaerobic system with higher daily biogas production.

Biomass amounts were determined by centrifuging the cultures and removing all possible liquid. The wet biomass value obtained from the biogas-fed culture was $2.46 \mathrm{~g}$, and the wet biomass value obtained from the air-fed culture was $3.29 \mathrm{~g}$. Thus, biomass yields for air and biogas are $3.29 \mathrm{~g} / \mathrm{L}$ and $2.46 \mathrm{~g} / \mathrm{L}$, respectively. As a result, the air-fed culture produced higher amount of biomass. This is due to the toxic effects of $\mathrm{H}_{2} \mathrm{~S}$ and $\mathrm{CH}_{4}$ in the biogas-fed culture, 
which became oxygen-limited. The results of the experimental biogas supply for astaxanthin production were very positive. The biogas-fed culture underwent earlier stress than the air-fed culture and was more successful at astaxanthin production. In Figure 14, a comparison of the stress stage cultures on the 18th day supports this idea.

At the end of the $22^{\text {nd }}$ day ( 12 days after the green phase and 10 days after the stimulation of astaxanthin production under stress conditions), the astaxanthin was harvested and produced. In Figure 15, the results of extraction with olive oil can be seen. The cell parts were left in the beakers used, and the upper phase was collected and transferred to clean beakers. After extraction, 12-mL extracts were obtained from both the biogas-fed and air-fed cultures.

The resulting extracted astaxanthin concentrations were $1231 \mathrm{mg} / \mathrm{L}$ from the biogas culture and $1385 \mathrm{mg} / \mathrm{L}$ from the air culture. The amounts of astaxanthin obtained per unit of biomass were determined as $6 \mathrm{mg} / \mathrm{g}$ and $5.1 \mathrm{mg} / \mathrm{g}$ for biogas and aerated cultures, respectively. Thus, although the air-fed culture produced a higher amount of algae biomass and therefore the amount of astaxanthin produced was higher, the biogas-fed culture yielded more successful results in terms of astaxanthin production per unit of biomass. It has been observed that algae can grow and use the $\mathrm{CO}_{2}$ in biogas.

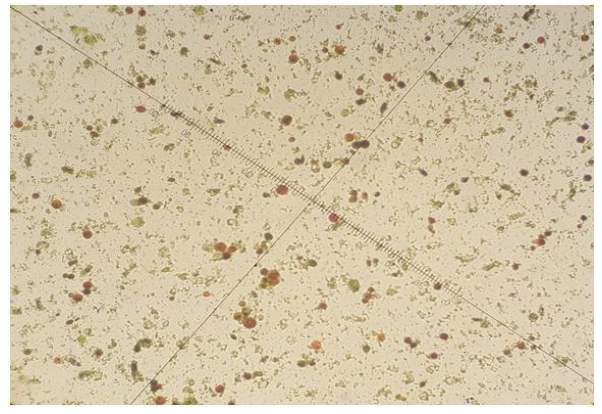

Figure 10. Results of extraction with hazelnut oil

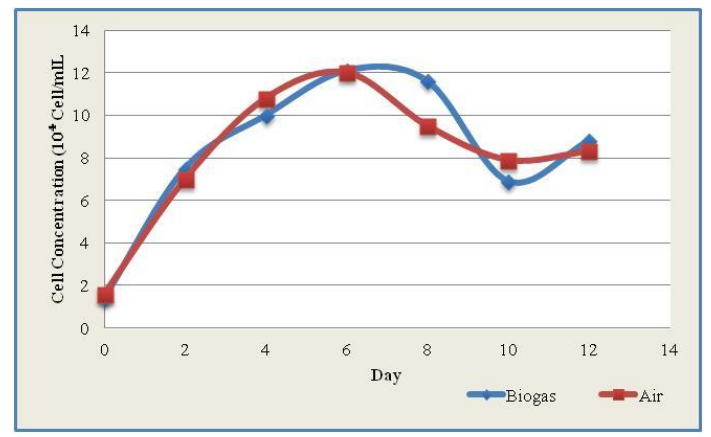

Figure 12. Cell concentration values for biogas-fed and air-fed algae cultures
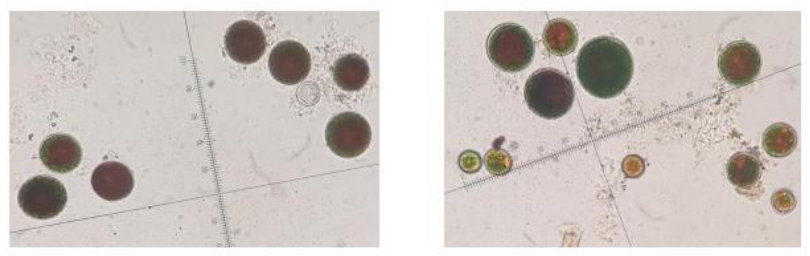

Figure 14. The cells on day 18 (biogas-fed (left) and air-fed (right))

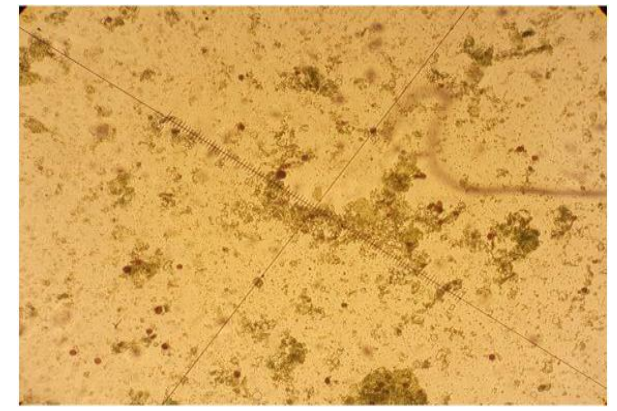

Figure 11. Results of extraction with olive oil

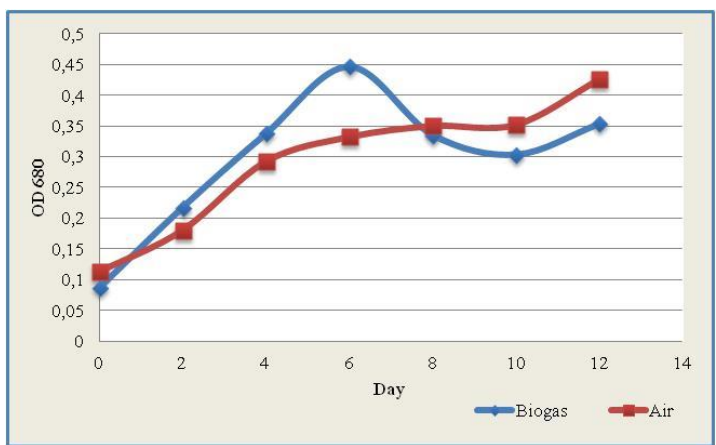

Figure 13. Absorbance values at $680 \mathrm{~nm}$ for biogasfed and air-fed algae cultures

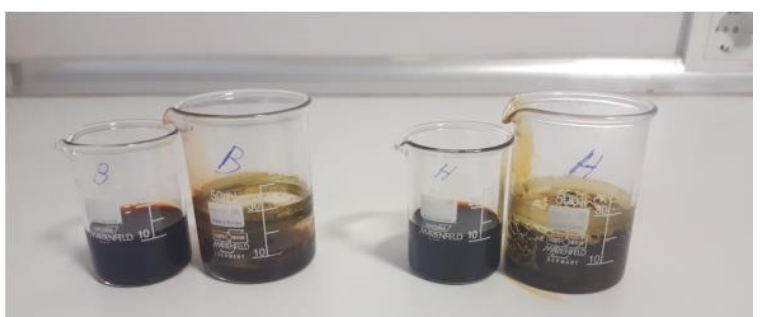

Figure 15. The extracts of astaxanthin 


\section{CONCLUSION}

As a result of this study, it was concluded that $H$. pluvialis algae can grow using the $\mathrm{CO}_{2}$ in biogas as a carbon source. The production results of the biogas-fed culture in the integrated system and the comparative (air-fed) culture under the same conditions were similar. In terms of both algae biomass production and the amount of astaxanthin produced, the comparative culture yielded better results. However, the biogas-fed culture performed better in terms of the amount of astaxanthin produced per unit of biomass. With this integrated system approach, biorefinery systems can be installed to make both biogas production and algae cultivation much more economical and environmentally friendly.

\section{Acknowledgements}

We wish to thank TUBITAK 2209 Industry Supported Bachelor Graduation Project Programme for financial support. Also special thanks to Prof. Dr. Nuri Azbar and Dr. Zeliha Demirel for advisory support.

\section{Declaration of Conflicting Interests and Ethics}

The authors declare no conflict of interest. This research study complies with research publishing ethics. The scientific and legal responsibility for manuscripts published in IJSM belongs to the author(s).

\section{Orcid}

Okyanus Yazgin (D) https://orcid.org/0000-0002-1895-3884

Tugba Keskin-Gundogdu (D) https://orcid.org/0000-0001-9354-7774

\section{REFERENCES}

[1]. Mann, G., Schlegel, M., Schumann, R., Sakalauskas, A. (2009). Biogas-conditioning with microalgae. Agron. Res. 7(1), 33-38.

[2]. Ambati, R.R., Moi, P.S., Ravi, S., Aswathanarayana, R.G. (2014). Astaxanthin: Sources, extraction, stability, biological activities and its commercial applications - A review. Marine Drugs, 12, 128-152. doi:10.3390/md12010128

[3]. Caponio, G., Massaro, V., Mossa, G., Mummolo, G. (2015). Strategic energy planning of residential buildings in a smart city: A system dynamics approach. Int. J. Eng. Bus. Manag., 7(20), 1-12. doi:10.5772/61768

[4]. Weiland, P. (2010). Biogas production: Current state and perspectives. Applied Microbiology and Biotechnology, 85, 849-860. doi: 10.1007/s00253-009-2246-7

[5]. Bagi, Z., Acs, N., Balint, B., Horvath, L., Dobo, K., Perei, K.R., Rakhely, G., et al. (2007). Biotechnological intensification of biogas production. Appl. Microbiol. Biotechnol., 76(2), 473-482. doi:10.1007/s00253-007-1009-6

[6]. Merlin Christy, P., Gopinath, L.R., Divya, D. (2014). A review on anaerobic decomposition and enhancement of biogas production through enzymes and microorganisms. Renewable and Sustainable Energy Reviews., 34, 167-173. doi:10.1016/j.rser.2014.03.010

[7]. Ranieri, L., Mossa, G., Pellegrino, R. , Digiesi, S. (2018). Energy recovery from the organic fraction of municipal solid waste: A real options-based facility assessment. Sustain.,10(2), 368-375. doi:10.3390/su10020368

[8]. Salihoglu, G., Salihoglu, N.K., Ucaroglu, S. ,Banar, M. (2018) Food loss and waste management in Turkey. Bioresource Technology 248, 88-99. doi:10.1016/j.biortech.201 7.06.083

[9]. Patil, V.S., Deshmukh, H.V. (2015). A review on Co-Digestion of Vegetable waste with Organic wastes for Energy Generation. International Research Journal of Biological Sciences, 4(6), 80-83. 
[10]. Bouallagui, H., Haourai, O., Touhami, Y., Ben Cheikh, R., Marouani, L., Hamdi, M. (2004). Effect of temperature on the performance of an anaerobic tubular reactor treating fruit and vegetable waste. Process Biochem., 39(12), 2143-2148. doi:10.1016/j.procbio.2003.11.022

[11]. Velmurugan, B., Ramanujam, R.A. (2011). Anaerobic digestion of vegetable wastes for biogas production in a fed-batch reactor. Int. J. Emerg. Sci., 1(3), 478.

[12]. Viturtia, A.M., Mata-Alvarez, J., Cecchi, F., Fazzini, G. (1989). Two-phase anaerobic digestion of a mixture of fruit and vegetable wastes. Biol. Wastes, 13(3-4), 257-267. doi:10.1016/0269-7483(89)90130-4

[13]. Raynal, J., Delgenès, J.P., Moletta, R. (1998). Two-phase anaerobic digestion of solid wastes by a multiple liquefaction reactors process. Bioresour. Technol., 65(1-2), 97-103. doi:10.1016/S0960-8524(98)00009-1

[14]. Bouallagui, H., Touhami, Y., Ben Cheikh, R., Hamdi, M. (2005). Bioreactor performance in anaerobic digestion of fruit and vegetable wastes. Process Biochemistry, 40(3-4), 989995. doi:10.1016/j.procbio.2004.03.007

[15]. Scano, E.A., Asquer, C., Pistis, A., Ortu, L., Demontis, V., Cocco, D. (2014). Biogas from anaerobic digestion of fruit and vegetable wastes: Experimental results on pilot-scale and preliminary performance evaluation of a full-scale power plant. Energy Convers. Manag., 77, 22-30. doi:10.1016/j.enconman.2013.09.004

[16].Sun, Q., Li, H., Yan, J., Liu, L., Yu, Z., Yu, X. (2015). Selection of appropriate biogas upgrading technology-a review of biogas cleaning, upgrading and utilisation. Renewable and Sustainable Energy Reviews., 51, 521-532. doi:10.1016/j.rser.2015.06.029

[17]. Guerin, M., Huntley, M.E., Olaizola, M. (2003). Haematococcus astaxanthin: Applications for human health and nutrition. Trends in Biotechnology, 21(5), 210-216. doi:10.1016/S0167-7799(03)00078-7

[18].Shah, M.M.R., Liang, Y., Cheng, J.J. , Daroch, M. (2016). Astaxanthin-producing green microalga Haematococcus pluvialis: From single cell to high value commercial products. Frontiers in Plant Science, 7, 531-563. doi:10.3389/fpls.2016.00531

[19]. Higuera-Ciapara, I., Félix-Valenzuela, L., Goycoolea, F.M. (2006). Astaxanthin: A review of its chemistry and applications. Critical Reviews in Food Science and Nutrition, 46(2), 185-196 doi:10.1080/10408690590957188

[20].Xi, T., Kim, D. G., Roh, S. W., Choi, J. S., Choi, Y. E. (2016). Enhancement of astaxanthin production using Haematococcus pluvialis with novel LED wavelength shift strategy. Appl. Microbiol. Biotechnol., 100(14), 6231-6238. doi:10.1007/s00253-016-7301-6

[21]. Boonnoun, P., Kurita, Y. (2016). Wet Extraction of Lipids and Astaxanthin from Haematococcus pluvialis by Liquefied Dimethyl Ether. J. Nutr. Food Sci., 4(5), 1000305 doi:10.4172/2155-9600.1000305

[22]. Kang, C.D., Sim, S.J. (2008). Direct extraction of astaxanthin from Haematococcus culture using vegetable oils. Biotechnol. Lett., 30(3), 441-444. doi:10.1007/s10529-007-9578-0

[23]. Samorì, C., Pezzolesi, L., Galletti, P., Semeraro, M., Tagliavini, E. (2019). Extraction and milking of astaxanthin from: Haematococcus pluvialis cultures. Green Chem. (accepted; in press). doi:10.1039/c9gc01273g

[24]. Rao, A.R., Sarada, R., Ravishankar, G.A. (2007). Stabilization of astaxanthin in edible oils and its use as an antioxidant. J. Sci. Food Agric., 87(6), 957-965. doi:10.1002/jsfa. 2766

[25]. Imamoglu, E., Vardar Sukan, F., Conk Dalay, M. (2007). Effect of Different Culture Media and Light Intensities on Growth of Haematococcus pluvialis. Int. J. Nat. Eng. Sci., 1(3), 05-09.

[26]. Azbar, N., Dokgöz, F.T., Keskin, T., Eltem, R., Korkmaz, K.S., Gezgin, Y., Akbal, Z., et al. (2009). Comparative evaluation of bio-hydrogen production from cheese whey 
wastewater under thermophilic and mesophilic anaerobic conditions. Int. J. Green Energy., 6,192-200.

[27]. Qiao, W., Yan, X., Ye, J., Sun, Y., Wang, W., Zhang, Z. (2011). Evaluation of biogas production from different biomass wastes with/without hydrothermal pretreatment. Renew. Energy., 36(12), 3313-3318. doi:10.1016/j.renene.2011.05.002

[28]. Bouallagui, H., Torrijos, M., Godon, J.J., Moletta, R., Cheikh, R.B., Touhami, Y., Delgenes, J.P., et al. (2004). Two-phases anaerobic digestion of fruit and vegetable wastes: Bioreactors performance. Biochem. Eng. J., 21(2), 193-197. doi:10.1016/j.bej.2004.05.0 01

[29]. Imamoglu, E., Dalay, M.C., Sukan, F. V. (2009). Influences of different stress media and high light intensities on accumulation of astaxanthin in the green alga Haematococcus pluvialis. N. Biotechnol., 26(3-4), 199-204. doi:10.1016/j.nbt.2009.08.007 